\title{
Retention levels of vegetable extractable beta-carotene preserved in virgin coconut oil and unadulterated honey
}

\author{
Mungai, Z. M., "Nawiri, M. P. and Nyambaka, H. N.
}

Kenyatta University, P.O Box 43844-00100 Nairobi, Kenya

\begin{abstract}
Article history:
Received: 16 May 2017

Received in revised form:

28 June 2017

Accepted: 29 June 2017

Available Online: 29 June 2017
\end{abstract}

\section{Keywords:}

Amaranthus,

Beta-carotene preservation, Honey,

Coconut oil,

Antioxidant activity

DOI:

http://doi.org/10.26656/

fr.2017.5.051

\begin{abstract}
Dark green leafy vegetables such as Amaranthus spp. are known to be good sources of beta -carotene, a pro-vitamin A carotenoid with highly potent antioxidant property. As an antioxidant, beta-carotene scavenges for electron and thus terminates chain reactions, prevents recurrence and formation of unstable oxygen which otherwise initiate a chain reaction leading to such cases as cancer. While beta-carotene is supplied from consuming vegetables to provide vitamin $\mathrm{A}$, it is also given as a supplement in cases of deficiency. However, it is highly degraded in the presence of light, heat, and oxygen posing a challenge to the methods of its preservation. Coconut oil and honey are popularly consumed in many countries facing vitamin A deficiency as good antioxidants and yet their role in preservation is largely unknown. The study reports the retention of betacarotene extracted from Amaranthus spp. and separately preserved in virgin coconut oil (VCO) and unadulterated honey for up to six months. HPLC and DPPH assay were used to determine beta-carotene and antioxidant activity respectively. Virgin coconut oil and honey had significantly different $(\mathrm{p}<0.001)$ antioxidant activities of $65.12 \pm 0.70$ and $81.51 \pm 1.39 \%$ radical scavenging activity respectively that compared well with those of BHT and ascorbic acid. The concentration of beta-carotene preserved in VCO and unadulterated honey degraded by $90 \%$, though the final retention provided higher than the recommended daily allowance of retinol $(0.216 \pm 0.001$ and $0.312 \pm 0.003$ retinol activity equivalent respectively) when $100 \mathrm{mg}$ is consumed. Virgin coconut oil and unadulterated honey can preserve beta-carotene if high amounts are used.
\end{abstract}

\section{Introduction}

Vitamin A deficiency is a major issue in many developing countries where animal food is consumed minimally. Consumption of dark green leafy vegetables such as Amaranthus that are rich in the pro-vitamin A carotenoid, beta-carotene reduces vitamin A deficiency (Nyambaka and Ryley, 2001; Abukutsa-Onyango, 2002; Makombo et al., 2010; Nawiri et al., 2013). In places where dark green leafy vegetables are hardly available such as arid and semi-arid region, supplementation with retinol or beta-carotene is advised. Apart from being a pro-vitamin A carotenoid, beta-carotene is an antioxidant that scavenges for electrons, terminating the chain reaction which could otherwise be the genesis of myriad non-communicable diseases including cancer (Jordi and
Andreu, 2000). Supplementation with beta-carotene not only addresses vitamin A deficiency but also provides the body with the much-needed antioxidant that scavenges for free radicals responsible for non-infectious diseases. Beta-carotene can be extracted from dark green vegetables when readily available during the rainy season.

The characteristic conjugated double bond system in beta-carotene is prone to isomerism and oxidation process that causes instability towards light, oxygen, heat, acid and alkaline conditions, thus losing its antioxidant and pro-vitamin A properties (Jordi and Andreu, 2000). Some efforts have been reported for the preservation of beta-carotene and these include encapsulation in lipid-based matrices and storing under 
vacuum or in an inert medium such as nitrogen gas (Nyambaka and Ryley, 2001; Moraes et al., 2013). Such methods are expensive and thus hindering availability of beta-carotene to the needy in society. More investigations on the preservation of beta-carotene extracted from the vegetable matrix are therefore required.

Honey is an antioxidant rich in phenolic acids, carotenoids, and flavonoids. It also contains other antioxidants such as glucose, oxidase, catalase, ascorbic acid, carotenoid derivatives, organic acids, amino acids and proteins (Ferreira et al., 2009; Khalil et al., 2010). The preservative property of honey has been demonstrated by its prevention of lipid oxidation in ground poultry (McKibben and Engeseth, 2002). African traditional societies used honey in the preservation of pre -cooked meat by submerging it in honey. On the other hand, coconut oil, an immune-enhancer, an antibiotic and a drug that regulates body functions and defense mechanism have antioxidants properties and a longer shelf life that is attributed to phenolic compounds (Fife, 2005; Marina et al., 2008; Seneviratne and Dissanayake, 2008). Coconut oil has been reported to increase the shelf-life of poultry meat submerged in it through reducing moisture content and bacteria colony (Aritonang et al., 2009).

The two matrices, coconut oil, and honey were envisaged to be good preservatives for beta-carotene based on their underlying properties. This was investigated in order that a scientific contribution towards addressing the challenge posed by the degradation of beta-carotene can be realized. In addition, vegetables are perishable and therefore strategies to extract beta-carotene from them for preservation is a key aspect towards addressing nutritional related conditions/ diseases.

\section{Materials and methods}

\subsection{Chemical and reagents}

All chemicals and reagents used were analytical grade purchased through Kobian Kenya limited. Ascorbic acid, 2,2-Diphenyl-1picrylhydrazyl (DPPH) and beta-carotene standard (Type 1) and solvents acetonitrile, dichloromethane and methanol (HPLC grades) were obtained from Sigma Chemicals Company (St Louis, USA).

\subsection{HPLC instrumentation}

Acetonitrile:methanol:dichloromethane mobile phase in the ratio of 70:10:20 was made. Using isocratic elution, and at $0.8 \mathrm{~cm}^{3} / \mathrm{min}$ flow rate, $1 \mu \mathrm{L}$ of the sample was injected into a reverse-phase HPLC. A Column of $250 \times 4.6 \mathrm{~mm}$ internal diameter and $5 \mu \mathrm{m}$ particle size operated at $25-30 \mathrm{kgF}$ and its oven had a temperature of $40^{\circ} \mathrm{C}$. Deuterium lamp was used as the detector to obtain UV spectra at $450 \mathrm{~nm}$ wavelength. The mobile phase was allowed to run through HPLC instrument for 20 minutes before injecting the sample.

\subsection{Preparation of preservation matrices}

Virgin coconut oil (VCO), obtained from three coconut vendors in Kongowea market (Mombasa County) was prepared by a wet process to retain its antioxidant properties (Fife, 2005). Fresh coconuts were mechanically grated from the kernel and the milk squeezed out using a clean piece of cloth. Coconut milk obtained was then boiled above $100^{\circ} \mathrm{C}$ for an hour to allow water to evaporate. Honey in honey-combs, obtained from a farmer in Eldama-Ravine (Koibatek County). The honey-combs were placed in a hot water bath which allowed the honey to be squeezed out. The extracted matrices were then stored in air-tight bottle before used as a preservative for extracted beta-carotene.

\subsection{Determination of antioxidant properties in preservation matrices}

The method employed was as per Ferreira et al. (2009) but with slight modification. A blank was prepared using $0.002 \mathrm{~g}$ of DPPH dissolved in methanol in a volumetric flask and the volume adjusted to $100 \mathrm{~cm}^{3}$. The absorbance of this solution was determined in triplicates using Jenway $6300 \mathrm{UV}$-Visibleat $517 \mathrm{~nm}$. The value obtained was used as the standard value for antioxidant properties.

Methanolic extract of VCO and unadulterated honey were prepared by separately placing $5 \mathrm{~g}$ of the matrices in $20 \mathrm{~cm}^{3}$ methanol (HPLC grade) and concentrated using a rotatory evaporator at $40^{\circ} \mathrm{C}$. Exactly $2 \mathrm{~cm}^{3}$ of the extract was placed in a test tube, $4 \mathrm{~cm}^{3}$ DPPH added and the mixture kept for 30 minutes in the dark to allow decolorization. The absorbance of the matrices was then determined in triplicates by UV-visible at a wavelength of $417 \mathrm{~nm}$. The absorbances were used to calculate $\%$ radical scavenging activities (\%RSA). Determination of $\%$ RSA of synthetic antioxidants (butylated hydroxytoluene (BHT) and ascorbic acid) was determined using their absorbances. The above procedure was repeated using $5 \mathrm{~g}$ of each synthetic antioxidant and the absorbance measured. 
\%RSA was determined as shown in Equation 1.

$$
\left.\% \operatorname{RSA}=\left[\left(\mathrm{A}_{\mathrm{DPPH}}-\mathrm{A}_{\mathrm{s}}\right) / \mathrm{A}_{\mathrm{DPPH}}\right)\right] \times 100
$$

Where $A_{D P P H}$ is the absorption of the blank and $A_{s}$ is the absorption of the sample (Eurachem, 1998).

\subsection{Extraction of beta-carotene}

Approximately $1500 \mathrm{~g}$ of Amaranthus spp. was obtained from Githurai market, Nairobi County and transported to Kenyatta University Chemistry Department laboratories and thoroughly washed with distilled water. Extraction of the carotenoid was done as described by Rodriguez-Amaya and Kimura (2005) with slight modification. The vegetables were blanched in water boiling at $90^{\circ} \mathrm{C}$ for two minutes. The leaves were blended with celite powder into a smooth paste.

Exactly $15 \mathrm{~g}$ of homogenous paste was placed in a conical flask and $50 \mathrm{~cm}^{3}$ of cold acetone was added in small portions during sonication. The mixture was sonicated for about 10 minutes, the extract filtered and extraction repeated until there was no more color on the residue. The extract was then partitioned with $25 \mathrm{~cm}^{3}$ of petroleum ether in a separating funnel and $10 \mathrm{~g}$ of BHT added. The lower chlorophyll layer was allowed to drain and the petroleum ether layer washed with $0.1 \%$ potassium hydroxide in ethanol. The mixture was allowed to stand for about 15 minutes lower layer drained and then washed (up to 5 times) with distilled water to remove any impurities. The carotenoid collected was dried using anhydrous sodium sulphate and then concentrated using a rotatory evaporator at $30^{\circ} \mathrm{C}$.

\subsection{Storage of beta-carotene in preservative matrices}

The carotenoid extract was preserved in VCO and honey in the ratio of $30 \mathrm{mg}$ to $15 \mathrm{~g}$ of $\mathrm{VCO}$ and homogenized by stirring in a stream of nitrogen gas. Using a syringe, The mixture, in $10 \mathrm{~g}$ portions was stored in an inert atmosphere at room temperature in brown airtight vials that had dry nitrogen blown. Beta-carotene levels were monitored on the first day, after two weeks and then monthly for six months using RP-HPLC.

\subsection{Determination of beta-carotene}

Stock solution of beta-carotene standard was prepared by dissolving $1 \mathrm{mg}$ in $2 \mathrm{~cm}^{3}$ of analytical grade methanol and further diluted to obtain a series of solutions for the calibration curve. Method validation was determined using recovery test where $1 \mathrm{mg}$ of betacarotene standard was spiked in $50 \mathrm{mg}$ of Amaranthus spp. vegetables. The accuracy of extraction was then determined using equation 2 .

$$
\% \text { Recovery }=\frac{\mathrm{C}_{\mathrm{F}}-\mathrm{C}_{\mathrm{U}}}{\mathrm{C}_{\mathrm{A}}} \times 100
$$

Where $C_{u}$ is the concentration in the unspiked sample, $\mathrm{C}_{\mathrm{A}}$ is the concentration of spike (added solution) and $\mathrm{C}_{\mathrm{F}}$ is the concentration determined in the spiked sample.

Using $1 \mathrm{~cm}^{3}$ of HPLC grade methanol, reconstitution $1 \mathrm{mg}$ of the unadulterated honey and VCO were done separately. By injecting $1 \mathrm{~mL}$ these solutions, the presence of beta-carotene was determined in the matrices.

The difference between the concentration of betacarotene in the matrices and that which was already in matrices gave the amount of beta-carotene that was preserved. This is indicated by equation 3 .

$$
\mathrm{BC}=\mathrm{BC}(\mathrm{f})-\mathrm{BC}(\mathrm{m})
$$

Where, $\mathrm{BC}$ beta-carotene in honey or $\mathrm{VCO}, \mathrm{BC}(\mathrm{f})$ betacarotene in the formulation and $\mathrm{BC}(\mathrm{m})$ beta-carotene in the matrix

Equation 4 was used to calculate the retinol activity equivalent (RAE) of beta-carotenein the ratio of 1:12 (1 $\mathrm{RAE}=12 \mu \mathrm{g}$ beta-carotene).

$$
1 \mathrm{RAE}=\mathrm{x}_{\mathrm{g}} \times \frac{1}{13}
$$

Where $\mathrm{X}_{\mathrm{s}}=$ concentration of beta-carotene in the sample

\subsection{Data analysis}

One way ANOVA was used to measure significant differences between means of concentration levels of beta-carotene at $95 \%$ and means separated using Student Newman Keul Test.

\section{Results and discussion}

\subsection{Antioxidant activities of virgin coconut oil and honey}

Table 1. Mean $( \pm \mathrm{SD})$ antioxidant activities and levels of betacarotene in unadulterated honey and virgin coconut oil

\begin{tabular}{ccc}
\hline Matrix & $\%$ RSA & $\begin{array}{c}\text { Concentration }(\mathrm{mg} / 100 \mathrm{~g}) \\
\text { DM n=3 }\end{array}$ \\
\hline VCO & $65.12 \pm 0.70$ & Below detectable limits \\
Honey & $81.51 \pm 1.39$ & $11.6 \pm 0.07$ \\
BHT & $77.47 \pm 0.10$ & \\
Ascorbic Acid & $70 \pm 0.17$ & \\
p-value & $<0.001$ & \\
\hline \multirow{2}{*}{ *VCO virgin } & coconut oil; *BHT $=$ butylated 4- \\
hydroxytoluene & &
\end{tabular}


The antioxidant activity expressed as percentage radical scavenging activity ( $\%$ RSA) for $\mathrm{VCO}$ and unadulterated honey is as shown in Table 1. Honey and VCO exhibited antioxidant activities that were not significantly different $(\mathrm{p}<0.001)$. A comparison of their $\%$ RSA with the synthetic antioxidants indicated that the two matrices have sufficient antioxidants which can scavenge radicals; attributed to the presence of phenolic compounds (Marina et al, 2008). In Table 1, the levels of beta-carotene of VCO and unadulterated honey prior to preservation are given. The results indicated that betacarotene levels were below detectable limits $(1.084 \mathrm{mg} /$

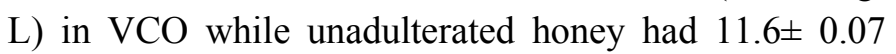
$\mathrm{mg} / 100 \mathrm{~g}(1.16 \mathrm{mg} / \mathrm{kg})$ beta-carotene. The level of betacarotene in honey was much lower compared to what was reported by Ferreira et al. (2009) who gave 84.98$90.78 \mathrm{mg} / \mathrm{ml}$ of methanolic extract of honey. The current study can attribute the differences to post-harvest handling Ferreira et al. (2009).

\subsection{Levels of beta-carotene with preservation}

A sample chromatograms of beta-carotene preserved in VCO is given in Figure 1. The carotenoid layer being a natural product gave several peak areas as shown by the chromatogram. Peak area representing beta-carotene was the one with retention time 3.564 .

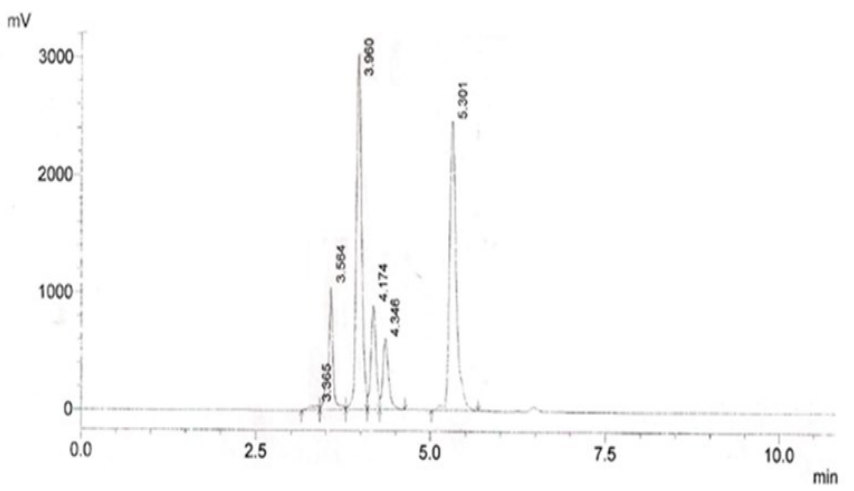

Figure 1. Chromatogram of beta-carotene preserved in VCO

The level of beta-carotene from fresh vegetables was $59.97 \pm 0.04 \mathrm{mg} / 100 \mathrm{~g}$ dry matter. Upon storage, the levels of beta-carotene reduced in both matrices. Table 2 shows the levels of beta-carotene preserved for 180 days while Figure 2 is the degradation pattern of beta-carotene in the two matrices with time. As shown in Table 2, the levels of beta-carotene in VCO significantly dropped $(\mathrm{p}<0.5)$ from $30.33 \pm 0.08 \mathrm{mg} / 100 \mathrm{~g}$ to $3.00 \pm 0.01 \mathrm{mg} / 100 \mathrm{~g}$ dry matter. A similar trend was seen in unadulterated honey where levels of beta-carotene dropped from $29.67 \pm 0.04$ to $5.10 \pm 0.02 \mathrm{mg} / 100 \mathrm{~g}$ dry matter $(\mathrm{p}<0.5)$. Rapid reduction within the first 3 months of storage by 21.33 $\mathrm{mg}(70.3 \%)$ in $\mathrm{VCO}$, with the rest occurring $90-180$ days (28.1\%) (Figure 2). Similarly, $21.79 \mathrm{mg}$ (73.4\%)
Table 2. Mean levels of beta-carotene preserved in nitrogen, honey and coconut oil for 180 days

\begin{tabular}{cccc}
\hline \multirow{2}{*}{ Days } & \multicolumn{3}{c}{ Concentration mg/100g DM (Mean \pm SD), $\mathrm{n}=3$} \\
\cline { 2 - 4 } & NBC & VCOBC & HBC \\
\hline 0 & $9.48 \pm 0.02^{\mathrm{a}}$ & $30.33 \pm 0.08^{\mathrm{a}}$ & $29.67 \pm 0.04^{\mathrm{a}}$ \\
14 & $9.67 \pm 0.17^{\mathrm{a}}$ & $25.00 \pm 0.04^{\mathrm{b}}$ & $28.76 \pm 0.12^{\mathrm{b}}$ \\
31 & $9.38 \pm 0.13^{\mathrm{a}}$ & $17.00 \pm 0.02^{\mathrm{c}}$ & $14.78 \pm 0.06^{\mathrm{c}}$ \\
60 & $9.41 \pm 0.01^{\mathrm{a}}$ & $9.00 \pm 0.03^{\mathrm{d}}$ & $8.74 \pm 0.03^{\mathrm{d}}$ \\
90 & $9.50 \pm 0.03^{\mathrm{a}}$ & $9.00 \pm 0.01^{\mathrm{e}}$ & $7.88 \pm 0.01^{\mathrm{e}}$ \\
120 & $9.48 \pm 0.02^{\mathrm{a}}$ & $8.00 \pm 0.01^{\mathrm{f}}$ & $6.31 \pm 0.01^{\mathrm{f}}$ \\
150 & $9.65 \pm 0.20^{\mathrm{a}}$ & $3.00 \pm 0.02^{\mathrm{g}}$ & $5.22 \pm 0.02^{\mathrm{g}}$ \\
180 & $9.45 \pm 0.08^{\mathrm{a}}$ & $3.00 \pm 0.01^{\mathrm{h}}$ & $5.10 \pm 0.02^{\mathrm{h}}$ \\
$\mathrm{p}$-values & $>0.05$ & $<0.001$ & $<0.001$ \\
\hline
\end{tabular}

*Mean values followed by different small letter in the same column are significantly different ( $\alpha=0.05$, One-way ANOVA, SNK-test)

VCOBC is beta-carotene in virgin coconut oil, HBC is betacarotene in honey and NBC is beta-carotene in nitrogen

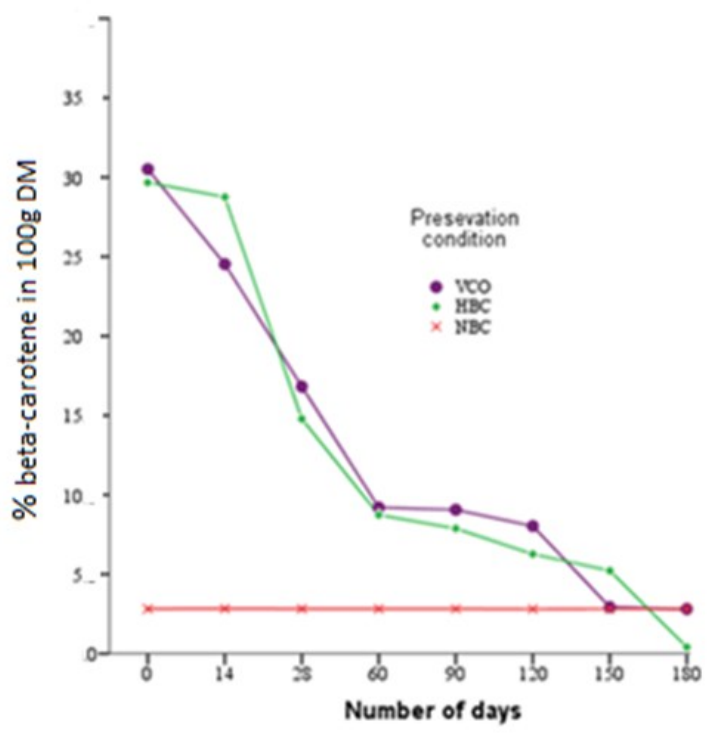

Figure 2. Beta-carotene degradation with storage

degraded in unadulterated honey within the first three months compared to $21.5 \%$ in the subsequent months. The reduced rate of degradation after three months may suggest the depletion of chemicals responsible for reacting with beta-carotene, suggesting that preserving higher amounts of beta-carotene in the matrices will result in lower degradation. The results imply $9.89 \%$ beta -carotene was preserved in VCO while $17.19 \%$ was retained in honey (Figure 2). The degradation pattern of the two matrices did not have a significant difference (Pvalue $=0.556)$ in their preservative properties. The presence of organic acids in the matrices of preservation and other compounds such as hydrogen peroxide contained in unadulterated honey can be attributed to the 
degradation of beta-carotene. (McKibben and Engeseth, 2002; Bang et al., 2003; Ferreira et al., 2009). Betacarotene preserved in nitrogen (NBC), which was a control, did not show a significant difference in levels of preserved beta-carotene as an inert medium doesn't allow degradation (Nyambaka and Ryley, 2001; Moraes et al., 2013).

The amount of beta-carotene at each stage of storage was translated into available vitamin $\mathrm{A}$ as retinol activity equivalent (Table 3). The retinol activity equivalent of beta-carotene retained in VCO ranged from $2.347 \pm 0.006$ to $0.216 \pm 0.001$ and in unadulterated honey varied from $2.282 \pm 0.003$ to $0.302 \pm 0.003$. Daily requirements for vitamin A ranges from $400 \mu \mathrm{g}$ for infants and $1300 \mu \mathrm{g}$ for an adult (Canada Health, 2014) indicating that if one consumes $100 \mathrm{mg}$ of beta-carotene in VCO or honey daily meets the vitamin A requirements (Canada Health, 2014; National Institute of Heath, 2013).

Table 3. Retinol activity equivalent from beta-carotene levels preserved in coconut oil and honey with storage

\begin{tabular}{ccc}
\hline \multirow{2}{*}{ Days } & Calculated & RAE \\
\cline { 2 - 3 } & VCOBC & HBC \\
\hline 0 & $2.347 \pm 0.006^{\mathrm{a}}$ & $2.282 \pm 0.003^{\mathrm{a}}$ \\
14 & $1.887 \pm 0.001^{\mathrm{b}}$ & $2.212 \pm 0.009^{\mathrm{b}}$ \\
31 & $1.294 \pm 0.001^{\mathrm{c}}$ & $1.137 \pm 0.005^{\mathrm{c}}$ \\
60 & $0.708 \pm 0.003^{\mathrm{d}}$ & $0.672 \pm 0.002^{\mathrm{d}}$ \\
90 & $0.697 \pm 0.002^{\mathrm{e}}$ & $0.606 \pm 0.001^{\mathrm{e}}$ \\
120 & $0.618 \pm 0.002^{\mathrm{f}}$ & $0.482 \pm 0.001^{\mathrm{f}}$ \\
150 & $0.226 \pm 0.001^{\mathrm{g}}$ & $0.402 \pm 0.002^{\mathrm{g}}$ \\
180 & $0.216 \pm 0.001^{\mathrm{h}}$ & $0.302 \pm 0.003^{\mathrm{h}}$ \\
\hline
\end{tabular}

VCOBC is Calculated retinol activity equivalent of betacarotene in honey. HBC is calculated retinol activity of betacarotene in honey

\section{Conclusion}

Virgin coconut oil and unadulterated honey have antioxidant properties that are sufficient. In the 180 days of preservation, the two matrices had preservative properties although degradation of beta-carotene occurred. By the end of preservation period degradation occurred, however, $10 \%$ of beta-carotene was preserved. Despite the degradation, the retained amount provides the required daily allowances for retinol. Virgin coconut oil and unadulterated honey can only retain high amounts when high amounts of beta-carotene are preserved.

\section{References}

Abukutsa-Onyango, M.O. (2002). Market survey on African indigenous vegetables in western Kenya. In Proceedings of the second horticultural seminar on sustainable horticultural production in the tropics. Jomo Kenyatta University of Agriculture and Technology (JKUAT), 39-46.

Aritonang, S.N., Martineli, E. and Eltiana, R. (2009). The Effect of the Submersion Length's in Virgin Coconut Oil on the Shelf Life of Chicken Meat under Room Temperature Storage. Pakistan Journal of Nutrition, 8, 100-102.

Bang, M., Buntting, C. and Molan, P. (2003). The effect of dilution on the rate of hydrogen peroxide production in honey and its implication for healing wounds. The Journal of Alternative Medicine, 9, 276 -273 .

Canada Health (2014). Health Canada's Proposed Changes to the Daily Values (DVs) for Use in Nutrition Labelling. Canada: Bureau of Nutritional Sciences, Food Directorate, Health Products and Food Branch.

Eurachem. (1998). The fitness of purpose of Analytical Methods. A laboratory guide to method validation and related. Retrieved from Eurachem website: https://www.eurachem.org/index.php/publications/ pubarch/143-gdmv98

Ferreira, I.C., Aires, E., Barreira, J. and Estevinho, L.M. (2009). Antioxidant activity of Portuguese honey samples: Different contributions of the entire honey and phenolic extract. Food Chemistry, 114, 14381443.

Fife, B. (2005). Coconut cures: Preventing and treating common health problems with coconut. London: Piccadilly Books, Ltd.

Jordi, O. and Andreu, P. (2000). Chromatographic determination of carotenoids in foods. Journal of Chromatography Analysis, 881, 543-555.

Khalil, M.I., Sulaiman, S.A. and Boukraa, L. (2010). Antioxidant properties of honey and its role in preventing health disorder. The Open Nutraceuticals Journal, 3, 6-16.

Makombo, N.D., Shoko, M.D. and Mtaita, T.A. (2010). Nutrient content of Amaranth (Amaranthus cruentus L.) under different processing and preservation methods. World Journal of Agricultural Science, 6, 639-643.

Marina, A.M., Che Man, Y.B., Nazimah, S.A.H. and Amin, I. (2008). Antioxidant capacity and phenolic acids of virgin coconut oil. International Journal of 
Food Sciences and Nutrition, 60, 114-123.

McKibben, J. and Engeseth, N.J. (2002). Honey as a protective agent against lipid oxidation in ground turkey. Journal of Agricultural and Food Chemistry, 50, 592-595.

Moraes, M., Carvalho, J.M.P., Silva, C.R., Cho, S., Sola, M.R. and Pinho, S.C. (2013). Liposomes encapsulating beta-carotene produced by the proliposomes method: characterisation and shelf life of powders and phospholipid vesicles. International Journal of Food Science and Technology, 48, 274 282.

National Institute of Heath (2013). Fact sheet for health professionals. Required daily allowance for Vitamin A. Retrieved from U.S. Department of Health and Human Services, National Institutes of Health website: https://ods.od.nih.gov/factsheets/VitaminAHealthProfessional/

Nawiri, M.P., Nyambaka, H. and Murungi, J.I. (2013). Sun-dried cowpeas and amaranth leaves recipe improves $\beta$-carotene and retinol levels in serum and hemoglobin concentration among preschool children. European Journal of Nutrition, 52, 583-589.

Nyambaka, H.N. and Ryley, J. (2001). Degradative provitamin A active compounds of all-trans- $\beta$-carotene in dehydrated dark green leafy vegetables. Bulletin of the Chemical Society of Ethiopia, 15, 57-64.

Seneviratne, K.N. and Dissanayake, D.M.S (2008). Variation of phenolic content in coconut oil extracted by two conventional methods. International Journal of Food Science and Technology, 43, 597-602. 